\title{
Effects of a Psychoeducational Program on Caregivers of Patients with Dementia
}

\author{
Charlotte Damien ${ }^{\mathrm{a}}$ Sophie Elands ${ }^{\mathrm{a}}$ Delphine Van Den Berge ${ }^{\mathrm{a}}$ \\ Jean-Christophe Bier ${ }^{\mathrm{a}}$ \\ ${ }^{a}$ Department of Neurology, Université Libre de Bruxelles/Hopital Erasme, Brussels, Belgium
}

\section{Keywords}

Dementia · Caregiver · Institutionalization .

Psychoeducation · Burden

\begin{abstract}
Background: The number of demented patients has increased significantly in recent years. The many challenges that dementia causes increase the stress of their caregivers and lead to shortening the time to institutionalization compared to the general population. A psychoeducational program for these accompanying persons was set up in Brussels. This type of program resulted in a 557-day delay in institutionalization in New York City. The objective of our study was to check whether our program also has such an impact, but also to see its potential effect on the psychobehavioral disorders of patients and the burden of caregivers. Methods: We recruited two groups without randomization: psychoeducated caregivers and caregivers interested in the program and contacted regularly (every 6 months) without having participated. They were all contacted by telephone and responded to the NCPI and Zarit Burden Scale (ZBS) questionnaires. Results: We could not demonstrate any significant impact, either on the institutionalization delay $(p=0.960)$, on
\end{abstract}

karger@karger.com

(c) 2020 S. Karger AG, Basel

www.karger.com/dem

Karger" the frequency of psychobehavioral disorders in demented patients ( $p>0.05)$, or on the burden of caregivers ( $p=0.403$ ). However, the survival rate among the demented patients with psychoeducated caregivers was significantly higher than that among the demented patients with nonpsychoeducated caregivers $(p<0.001)$. Conclusions: Our smallsample, nonrandomized study did not reveal any differences in institutionalization delay, caregiver burden, or perception of psychobehavioral disorders related to our psychoeducational program. A new study should be carried out on the impact of psychoeducation on the survival of demented patients, in view of our preliminary analyses.

(c) 2020 S. Karger AG, Basel

\section{Introduction}

Dementia is one of the major causes of disability and dependency and concerns around 46.8 million patients worldwide. This number is predicted to increase to over 130 million by 2050 [1]. Epidemiological studies carried out in Western Europe have shown the prevalence of dementia to increase with age and to be higher among women [2]. In 2011, the definition of dementia due to Alz- 


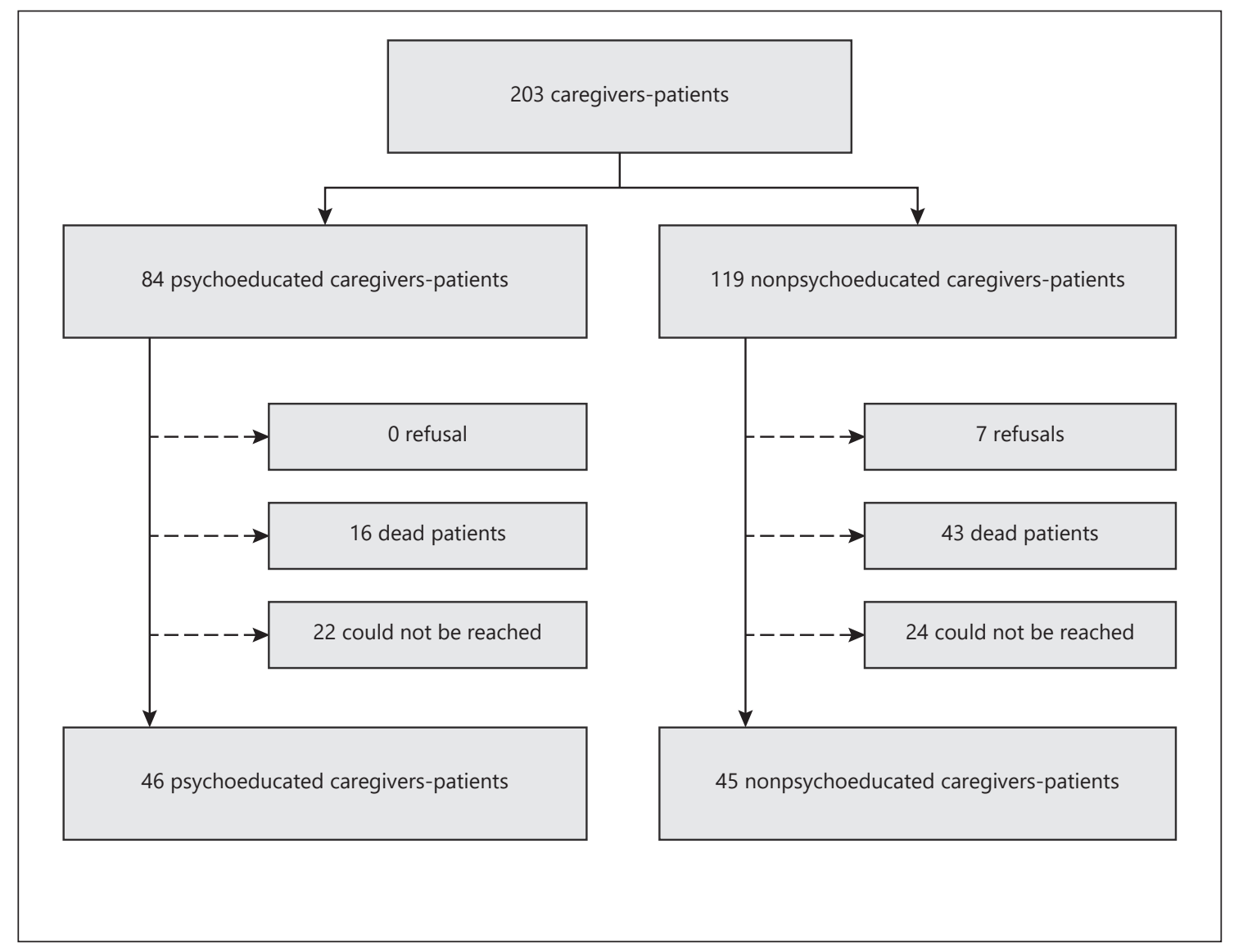

Fig. 1. Study flowchart.

heimer disease $(\mathrm{AD})$ required impairments in at least 2 neuropsychiatric or cognitive domains that are not better explained by nondegenerative or primary psychiatric disorders or systemic conditions [3]. In 2013, dementia syndrome has been revised into major neurocognitive disorder (MND) [4]. MND can be categorized into 5 main clinical etiologies: prion-related disorder, $\mathrm{AD}$, frontotemporal dementia (FTD), Lewy body dementia (LBD), and vascular dementia [5].

Given the irreversibility of these diseases, the caregiver, defined as the person who provides most of the care of the patient affected by MND, is expected to assume increased responsibilities as the patient progressively deteriorates. The term "caregiver burden" is often used and was defined by Zarit et al. [6] as "the degree to which a carer's emotional or physical health, social life or financial status has suffered as a result of caring for their relative."

Many patients with MND are eventually institutionalized, at a rate of about $20 \%$ in the first year after diagnosis, reaching $50 \%$ after 5 years, with the median delay ranging between 30 and 40 months [7]. Caregiver burden has been identified as a risk factor for nursing home placement [8-10].

Caregiver support, in the form of counseling programs and respite services, has proved effective in reducing or delaying the institutionalization of patients with MND, as well as improving the quality of life of the caregivers themselves [11-14]. In New York, Mittelman et al. [14] thus demonstrated the impact of their psychoeducational program (PP) on the spouses of patients with $\mathrm{AD}$ in delaying the need for institutionalization.

In this context, the memory clinic at our institution in Brussels has set up a PP for caregivers of patients with MND called "Pour mieux vivre avec la maladie d'Alzheimer" [15]. The aim of this study was to analyze the potential beneficial effects of our PP. The primary outcome was delay until institutionalization, whilst the secondary outcomes were the quality of life and degree of burden experienced by caregivers. 


\section{Subjects and Methods}

This is a single-center study conducted at Hopital Erasme, Brussels, Belgium, using a case-control design with retrospective inclusion of caregivers of patients with MND.

\section{Selection and Collected Data}

The "case" group included participants who had attended our $\mathrm{PP}$. The inclusion criteria for the case group were participation in the complete PP between February 2008 and September 2014, with agreement to undergo the telephone interview. The complete details about our PP are available in the online supplementary Appendices (see www.karger.com/doi/10.1159/000509169 for all online suppl. material,).

The "control" group included participants who were interested in our PP but had not participated in it. The inclusion criteria for the control group were recruitment and interest in the PP between July 2009 and September 2014, without participating before January 2015 , with agreement to undergo the telephone interview (see the flowchart shown in Fig. 1).

The exclusion criteria for both groups were:

- Death of the patient with dementia (by the time of the phone interview)

- Institutionalization prior to the PP

- Institutionalization and/or death during the PP

- Refusal to undergo the telephone interview

- Failure to reach the caregiver by telephone

- Data had been collected anonymously

For the caregivers of patients deceased prior to or during the $\mathrm{PP}$, only the patient's date of death (month and year) was collected. For the caregivers of patients institutionalized prior to or during the PP, only the patient's date of institutionalization (month and year) was collected.

The caregivers of patients still living at home answered two questionnaires during a telephone interview. The first questionnaire was the Zarit Burden Scale (ZBS) [16], and the second was the NCPI questionnaire derived from the Neuropsychiatric Inventory (NPI) questionnaire [17].

The NCPI questionnaire consists of questions about memory disorder, orientation disorder, communication/speaking disorder, apraxia, agnosia, thinking difficulties, and attentional disorder. The complete details about the NCPI questionnaire are available in the online supplementary Appendices.

The subtypes of MND were noted and classified according to the DSM-5 criteria into $\mathrm{AD}$, vascular MND, FTD, LBD, mixed MND (combined vascular and Alzheimer etiology), other dementia, and dementia of uncertain etiology [4].

The caregivers were classified as "spouse" or "other," with the latter category encompassing relations such as son/daughter, grandson/grand-daughter, mother/father, brother/sister, or friend. Other epidemiological data were collected from the medical files available from our institution, including the psychological support received by the caregiver, the number of medications taken by the caregiver, the formal care being given at home (nurse, healthcare assistant, etc.), and attendance at daycare centers by the patient.

\section{Statistics}

Statistical analyses were performed with SPSS software. Comparisons were done using $\chi^{2}$ and Fisher tests, the Mann-Whitney $\mathrm{U}$ test, and the Kruskal-Wallis test. Correlations were quantified
Table 1. Demographic and clinical characteristics of the patients and caregivers

\begin{tabular}{|c|c|c|}
\hline & $\begin{array}{l}\text { Cases } \\
(n=46)\end{array}$ & $\begin{array}{l}\text { Controls } \\
(n=45)\end{array}$ \\
\hline \multicolumn{3}{|l|}{ Patients } \\
\hline Median age (IQR), years & $77.5(68-81.75)$ & $79(70-82)$ \\
\hline Female, $n(\%)$ & $24(52.2)$ & $28(62.2)$ \\
\hline Median MMSE score (IQR) & $21.5(16-24)$ & $21.5(14.75-25)$ \\
\hline \multicolumn{3}{|l|}{ Subtype of dementia, $n(\%)$} \\
\hline $\mathrm{AD}$ & $16(34.8)$ & $29(64.4)$ \\
\hline VD & $4(8.7)$ & $5(11.1)$ \\
\hline FTD & $6(13)$ & $5(11.1)$ \\
\hline LBD & $2(4.4)$ & $2(4.4)$ \\
\hline Mixed & $8(17.4)$ & $3(6.7)$ \\
\hline Other & $1(2.2)$ & $0(0)$ \\
\hline Uncertain & $9(19.6)$ & $1(2.2)$ \\
\hline \multicolumn{3}{|l|}{ Caregivers } \\
\hline Median age (IQR), years & $58(49-74)$ & $64.5(49.5-77)$ \\
\hline Female, $n(\%)$ & $34(73.9)$ & $28(62.2)$ \\
\hline \multicolumn{3}{|l|}{ Patient-caregiver relation, $n(\%)$} \\
\hline Spouse & $24(52.2)$ & $22(48.9)$ \\
\hline Other & $22(47.8)$ & $23(51.1)$ \\
\hline Son/daughter & $21(45.7)$ & $18(40)$ \\
\hline Grandson/grand-daughter & $0(0)$ & $1(2.2)$ \\
\hline Friend & $0(0)$ & $2(4.4)$ \\
\hline Mother/father & $1(2.2)$ & $0(0)$ \\
\hline Brother/sister & $0(0)$ & $2(4.4)$ \\
\hline
\end{tabular}

$\mathrm{AD}$, Alzheimer disease; VD, vascular dementia; FTD, frontotemporal dementia; LBD, Lewy body dementia.

using the nonlinear Spearman correlation test. Kaplan-Meier estimation, with a log-rank test for comparison, was used to study the institutionalization delay. A $p$ value $<0.05$ was accepted as the threshold for statistical significance.

\section{Results}

The demographic and clinical characteristics at baseline of the patients with dementia and their main caregiver are summarized in Table 1. No significant differences were identified between the two groups $(p>0.05)$. The delay in institutionalization was not different between the patients with caregivers who had completed the PP and those with caregivers who had not (Fig. 2).

For a second analysis, we reanalyzed our data by adding 6 months to the duration of follow-up of the patient caregivers having completed the PP. We consider that 6 months corresponds to the delay between agreement to participate in the PP and actual enrollment in our program, because our program takes place twice a year. This second analysis did not reveal significant differences between the two groups either (Fig. 3). 


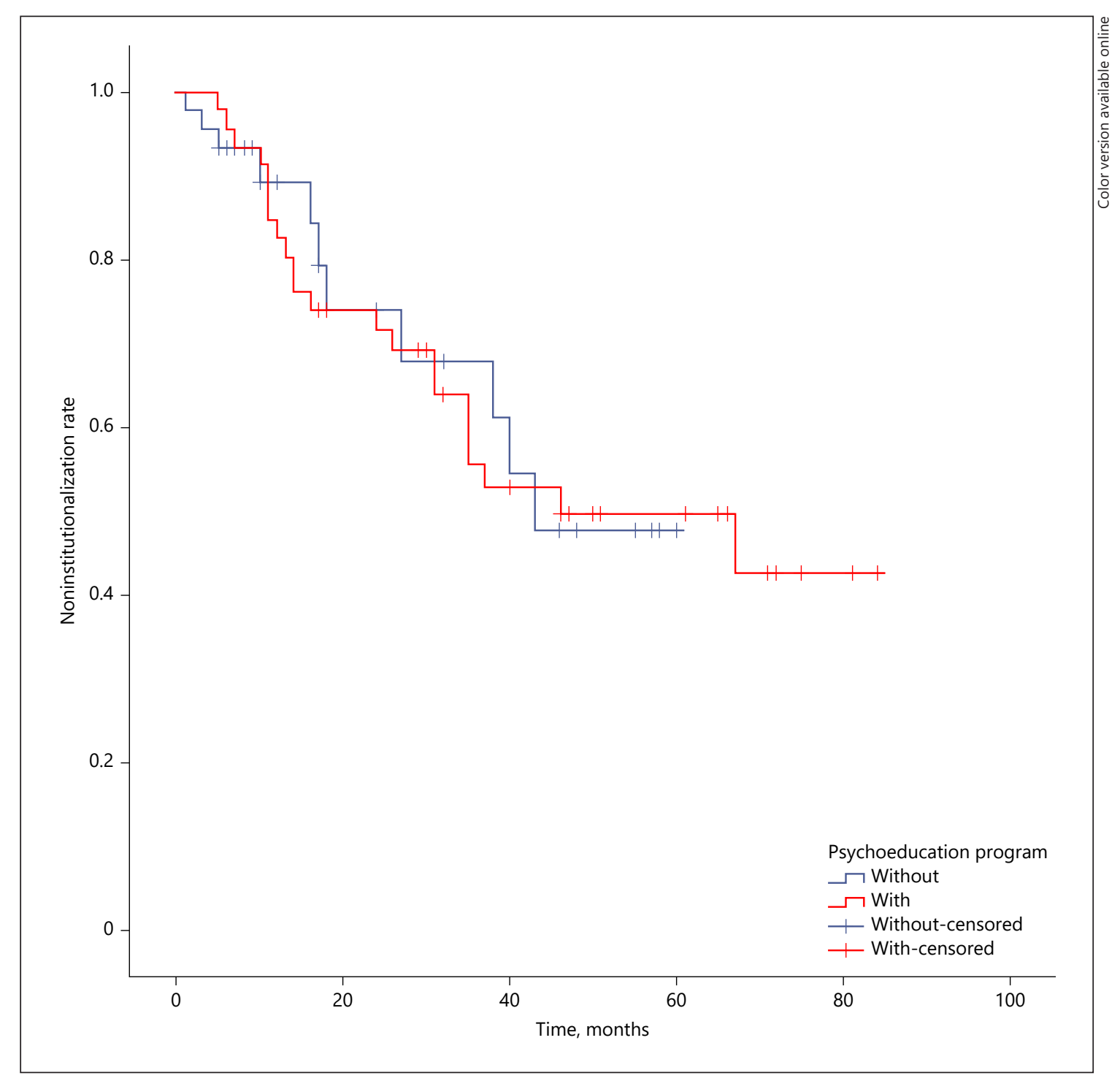

Fig. 2. Delay in institutionalization (log-rank test: $\left.\chi^{2}=0.003 ; \mathrm{DDL}=1 ; p=0.960\right)$.

The delay in institutionalization was not influenced by the age of the patient $(p=0.169)$, the age of the caregiver $(p=0.352)$, the sex of the patient $(p=0.651)$, the sex of the caregiver $(p=0.0692)$, or the Mini-Mental State Examination (MMSE) score $(p=0.085)$. However, the delay was affected by the subtype of MND. Indeed, patients with LBD and FTD were institutionalized earlier, followed by patients with $\mathrm{AD}$ and mixed dementia. In our cohort, patients with vascular dementia and other types of MND (e.g., Korsakoff syndrome) were not institutionalized, but these represented a very small proportion of our groups.

The relationship between the patient and their caregiver also had a significant impact on this delay $(p=$
$0.036)$, since patients with a spouse as a caregiver tended to be institutionalized at a later stage. No significant difference was observed between the group with and that without the PP with regard to psychobehavioral disorders of the patients (NPI total score, $p=0.42$; NPI distress total score, $p=0.956 ; \Delta \mathrm{NCPI}-\mathrm{NPI}$ total score, $p=0.813$; $\Delta$ NCPI - NPI distress total score, $p=0.782$ ).

The caregivers who participated in the PP did not show a lighter burden than those who had not participated, as expressed by the ZBS score $(p=0.403)$. Some demographic and clinical variables showed a significant impact on the behaviors of patients with dementia (Table 2 ) and the burden of caregivers (Table 3 ). 


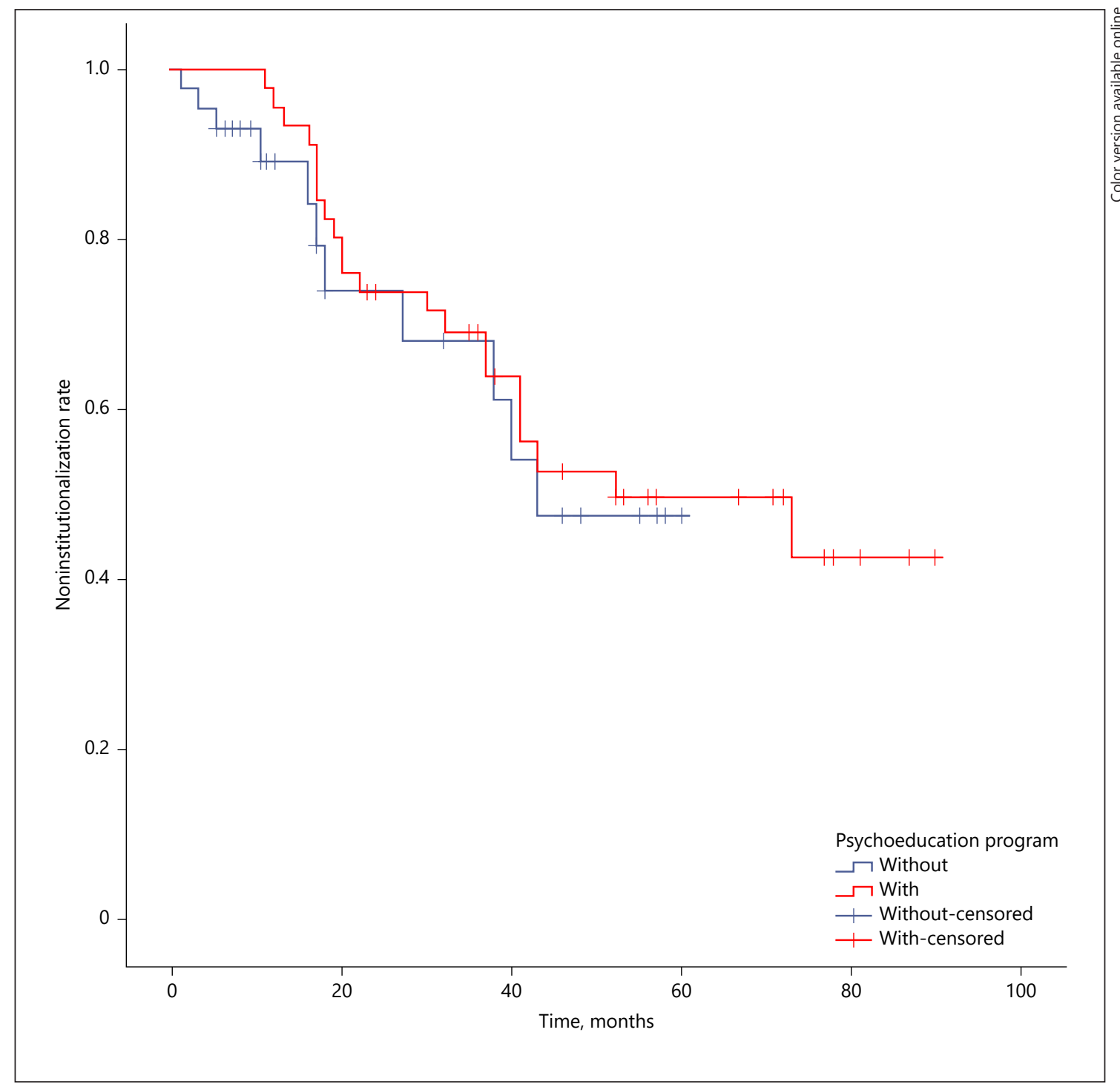

Fig. 3. Adjusted delay in institutionalization (log-rank test: $\chi^{2}=0.355 ; \mathrm{DDL}=1 ; p=0.551$ ).

Table 2. Impact of the demographic and clinical characteristics on psychobehavioral disorders

\begin{tabular}{|c|c|c|c|c|c|c|c|c|}
\hline \multirow[t]{2}{*}{ Variables } & \multicolumn{2}{|l|}{$\begin{array}{l}\triangle \mathrm{NCPI} \\
\text { total }\end{array}$} & \multicolumn{2}{|c|}{$\begin{array}{l}\Delta \mathrm{NCPI} \text { distress } \\
\text { total }\end{array}$} & \multicolumn{2}{|l|}{$\begin{array}{l}\text { NPI } \\
\text { total }\end{array}$} & \multicolumn{2}{|c|}{$\begin{array}{l}\text { NPI distress } \\
\text { total }\end{array}$} \\
\hline & rho & $p$ value & rho & $p$ value & rho & $p$ value & rho & $p$ value \\
\hline Patient age & -0.076 & 0.576 & -0.095 & 0.486 & 0.029 & 0.831 & -0.032 & 0.816 \\
\hline Patient sex & & 0.334 & & 0.969 & & 0.623 & & 0.679 \\
\hline Caregiver age & -0.054 & 0.7 & 0.021 & 0.879 & -0.245 & 0.074 & -0.304 & 0.026 \\
\hline Caregiver sex & & 0.685 & & 0.014 & & 0.134 & & 0.011 \\
\hline Relation patient-caregiver (spouse vs. other) & & 0.356 & & 0.348 & & 0.224 & & 0.034 \\
\hline MMSE score & -0.495 & $<0.001$ & -0.423 & 0.002 & -0.177 & 0.21 & -0.029 & 0.84 \\
\hline Type of dementia (AD + MD vs. FTD + LBD vs. VD + OD) & & 0.624 & & 0.372 & & 0.47 & & 0.159 \\
\hline Psychological support of caregiver & & 0.332 & & 0.941 & & 0.646 & & 0.965 \\
\hline Number of medications of caregiver & 0.018 & 0.891 & 0.134 & 0.317 & 0.062 & 0.645 & 0.03 & 0.821 \\
\hline Helps at home & & 0.072 & & 0.629 & & 0.409 & & 0.755 \\
\hline
\end{tabular}

Bold type denotes significance. AD, Alzheimer disease; MD, mixed dementia; FTD, frontotemporal dementia; LBD, Lewy body dementia; VD, vascular dementia; OD, other dementia. 


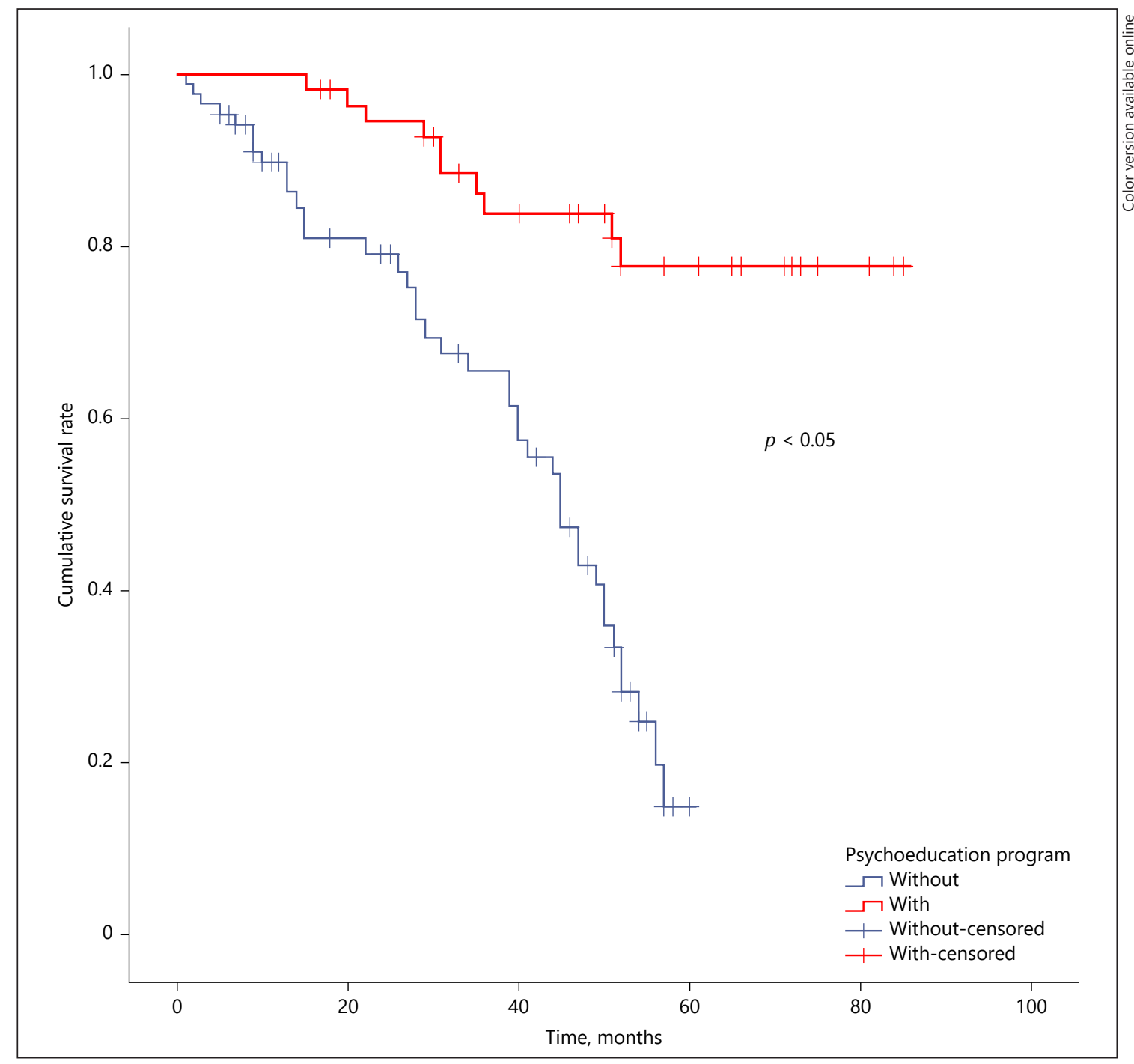

Fig. 4. Survival rates of the patients with $\mathrm{MND}$, comparing those with $\mathrm{PP}$ and those with non-PP caregivers. MND, major neurocognitive disorder; PP, psychoeducational program.

Table 3. Impact of the demographic and clinical characteristics on caregiver burden

\begin{tabular}{lcl}
\hline Variables & Rho & $p$ value \\
\hline Patient age & -0.21 & 0.878 \\
Caregiver age & -0.74 & 0.597 \\
Patient sex & & 0.548 \\
Caregiver sex & & 0.366 \\
Relation patient-caregiver (spouse vs. other) & & 0.562 \\
Type of dementia (AD + MD vs. FTD + LBD vs. VD + OD) & 0.5 & 0.701 \\
Number of medications of caregiver & & 0.969 \\
Psychological support of caregiver & & 0.45 \\
Daycare center for patients & & 0.597 \\
Helps at home & & 0.597 \\
\hline
\end{tabular}

$\mathrm{AD}$, Alzheimer disease; MD, mixed dementia; FTD, frontotemporal dementia; LBD, Lewy body dementia; VD, vascular dementia; OD, other dementia. 
Finally, patients without PP caregivers presented a significantly higher rate of mortality than those with PP caregivers ( $p<0.0001$; Fig. 4$)$.

\section{Discussion}

In our study, the PP did not result in a delay in institutionalization. As a limitation, when comparing the two groups, the initial PP starting times were not defined in the same way. In the group who completed the PP, the initial time was set as the beginning of the program, whereas in the group without the PP, the initial time was defined as the date of agreement to participate in the program. However, there is often a time lag of several months between the agreement date and the start of the PP. A means of overcoming this incongruity was to add 6 months to the follow-up time for the group who had completed the PP. However, this amendment did not lead to any significant difference between the two groups, perhaps because the added delay could have been longer than 6 months, since the PP only takes place twice a year. Another limitation is that the size of our population could be insufficient to identify an effect of the PP. Furthermore, several subtypes of MND were included in our population. A more restricted selection of patients - for example, only patients with $\mathrm{AD}$ - could maybe reveal an effect of the PP on the delay in institutionalization. A final limitation of the present study lies in the nonrandomized distribution of our samples. This could lead to potential biases, such as self-selection or selection bias. The group who completed the PP actually needed help (such as a program of support or psychological education) and would experience worsening without the PP. This group represents those who would benefit the most from the program.

Unlike the present study and a Dutch randomized multicenter trial looking at the impact of a family meeting intervention on the delay in institutionalization [18], Mittelman et al. [14] succeeded in identifying a benefit of their program in delaying institutionalization. However, one should take into consideration that this study took place in a different socioeconomic and cultural context, looking at Hispanic spouses living in New York City. This ethnic group is known to look after their relatives at home longer than caregivers of many other cultures [19]. These populations could thereby benefit more from support programs, particularly in delaying nursing home placement.

In Brussels, the patients with FTD or LBD had a shorter delay until nursing home placement than the patients with other subtypes of MND. LBD is known to be charac- terized by psychiatric symptoms such as depression [20], personality and behavioral (sexual or eating) changes, and disinhibition [21], leading to interpersonal and social difficulties, and thereby contributing to a high caregiver burden [22] and stress level [23]. In our study, caregiver stress was identified as a risk factor for earlier institutionalization for this subgroup. The distress experienced by caregivers related to behavioral disorders proved to be greater with FTD patients than with AD patients [24].

For patients with spouses as caregivers, nursing home placement occurred later than for patients with other types of caregiver. A similar impact has already been described for daycare center attendance [25]. Our data highlighted a tendency towards a shorter delay until institutionalization the older the patient was. However, this trend was not statistically significant. Yaffe et al. [8] obtained comparable statistically significant results in 2002. In the study by Yaffe et al., a MMSE score $<20$ points was a risk factor for earlier nursing home placement.

No significant variation was observed in NPI, NPCI, and ZBS scores in association with the PP, although these scores are based on the subjectivity of questionnaires filled in by caregivers $[26,27]$. No evidence of the efficacy of psychological intervention or support on caregiver burden has been published in the past. However, a lower caregiver burden ( $<10$ points on the ZBS) was clearly associated with later institutionalization [25].

Finally, survival was significantly longer in the group with caregivers having completed the PP. However, these results need to be interpreted with caution. The present study was not designed for this purpose. Patient comorbidities, cause of death, and treatments were not recorded, which would be crucial for interpreting this result.

\section{Conclusions}

In conclusion, in the present study, our PP did not have a significant impact by delaying institutionalization. However, the subtype of MND and the relationship of the caregiver with the patient did have a significant impact on the delay. In the future, a randomized controlled study looking at selected subtypes of MND, with an analysis of relevant demographic and clinical characteristics, could be beneficial for further investigation of the impact of the $\mathrm{PP}$ on caregivers.

Published in Celebration of the 30th Anniversary of the inception of Dementia and Geriatric Cognitive Disorders 1990-2020. 


\section{Statement of Ethics}

Written, informed consent was obtained from the patients or their authorized surrogates. The protocol of the study was approved beforehand by the Ethics Committee of Hopital Erasme in Brussels.

\section{Conflict of Interest Statement}

The authors have no conflicts of interest to declare.

\section{Funding Sources}

The PP "Pour mieux vivre avec la maladie d'Alzheimer" was funded by Hopital Erasme, the King Baudouin Foundation (Geert Noel Award), the National Lottery, Alzheimer Belgium, Novartis, Lundbeck, and Janssen-Cilag. None of these institutions were involved in the collection of data and redaction of the manuscript.

\section{Author Contributions}

C.D.: conception of the work; acquisition, analysis and interpretation of data; and redaction and revision of the manuscript. S.E.: acquisition and interpretation of data. D.V.D.B.: conception of the work and acquisition of data. J.-C.B.: conception of the work, acquisition of data, and revision of the manuscript.

\section{References}

1 Prince M, Wimo A, Guerchet M, GemmaClaire A, Wu Y-T, Prina M. World Alzheimer Report 2015: the global impact of dementia an analysis of prevalence, incidence, cost and trends. Alzheimer's Disease International; 2015. Available from: https://www.alz.co.uk/ research/WorldAlzheimerReport2015.pdf.

2 Bacigalupo I, Mayer F, Lacorte E, Di Pucchio A, Marzolini F, Canevelli M, et al. A Systematic Review and Meta-Analysis on the Prevalence of Dementia in Europe: Estimates from the Highest-Quality Studies Adopting the DSM IV Diagnostic Criteria. J Alzheimers Dis. 2018;66(4):1471-81.

3 McKhann GM, Knopman DS, Chertkow H, Hyman BT, Jack CR Jr, Kawas CH, et al. The diagnosis of dementia due to Alzheimer's disease: recommendations from the National Institute on Aging-Alzheimer's Association workgroups on diagnostic guidelines for Alzheimer's disease. Alzheimers Dement. 2011 May;7(3):263-9.

4 American Psychiatric Association. American Psychiatric Association, 2013. Diagnostic and statistical manual of mental disorders (5th ed.). 2013. Available from: https://doi.org/10.1176/ appi.books.9780890425596.744053.

5 Elahi FM, Miller BL. A clinicopathological approach to the diagnosis of dementia. Nat Rev Neurol. 2017 Aug;13(8):457-76.

6 Zarit SH, Todd PA, Zarit JM. Subjective burden of husbands and wives as caregivers: a longitudinal study. Gerontologist. 1986 Jun;26(3):260-6.

7 Luppa M, Luck T, Weyerer S, König HH, Brähler E, Riedel-Heller SG. Prediction of institutionalization in the elderly. A systematic review. Age Ageing. 2010 Jan;39(1):31-8.

8 Yaffe K, Fox P, Newcomer R, Sands L, Lindquist K, Dane K, et al. Patient and caregiver characteristics and nursing home placement in patients with dementia. JAMA. 2002 Apr;287(16):2090-7.

9 Gilley DW, McCann JJ, Bienias JL, Evans DA. Caregiver psychological adjustment and institutionalization of persons with Alzheimer's disease. J Aging Health. 2005 Apr;17(2):172-89.
10 Gaugler JE, Kane RL, Kane RA, Clay T, Newcomer R. Caregiving and institutionalization of cognitively impaired older people: utilizing dynamic predictors of change. Gerontologist. 2003 Apr;43(2):219-29.

11 Lawton MP, Brody EM, Saperstein AR. A controlled study of respite service for caregivers of Alzheimer's patients. Gerontologist. 1989 Feb;29(1):8-16.

12 Mittelman MS, Ferris SH, Shulman E, Steinberg G, Levin B. A family intervention to delay nursing home placement of patients with Alzheimer disease. A randomized controlled trial. JAMA. 1996 Dec;276(21):1725-31.

13 Belle SH, Burgio L, Burns R, Coon D, Czaja SJ, Gallagher-Thompson D, et al.; Resources for Enhancing Alzheimer's Caregiver Health (REACH) II Investigators. Enhancing the quality of life of dementia caregivers from different ethnic or racial groups: a randomized, controlled trial. Ann Intern Med. 2006 Nov; 145(10):727-38.

14 Mittelman MS, Haley WE, Clay OJ, Roth DL. Improving caregiver well-being delays nursing home placement of patients with Alzheimer disease. Neurology. 2006 Nov;67(9):1592-9.

15 Bier JC, Van den Berge D, de Wouters d'Oplinter N, Bosman N, Fery P. Evaluation of our psycho-educative program by participating caregivers [in French]. Rev Med Brux. 2010 Sep;31(4):315-9.

16 Zarit SH, Reever KE, Bach-Peterson J. Relatives of the impaired elderly: correlates of feelings of burden. Gerontologist. 1980 Dec;20(6):649-55.

17 Cummings JL, Mega M, Gray K, RosenbergThompson S, Carusi DA, Gornbein J. The Neuropsychiatric Inventory: comprehensive assessment of psychopathology in dementia. Neurology. 1994 Dec;44(12):2308-14.

18 Joling KJ, van Marwijk HW, van der Horst HE, Scheltens P, van de Ven PM, Appels BA, et al. Effectiveness of family meetings for family caregivers on delaying time to nursing home placement of dementia patients: a randomized trial. PLoS One. 2012;7(8):e42145.
19 Mausbach BT, Coon DW, Depp C, Rabinowitz YG, Wilson-Arias E, Kraemer HC, et al. Ethnicity and time to institutionalization of dementia patients: a comparison of Latina and Caucasian female family caregivers. J Am Geriatr Soc. 2004 Jul;52(7):1077-84.

20 Lanata SC, Miller BL. The behavioural variant frontotemporal dementia (bvFTD) syndrome in psychiatry. J Neurol Neurosurg Psychiatry. 2016 May;87(5):501-11.

21 Seeley WW, Crawford R, Rascovsky K, Kramer JH, Weiner M, Miller BL, et al. Frontal paralimbic network atrophy in very mild behavioral variant frontotemporal dementia. Arch Neurol. 2008 Feb;65(2):249-55.

22 Mioshi E, Bristow M, Cook R, Hodges JR. Factors underlying caregiver stress in frontotemporal dementia and Alzheimer's disease. Dement Geriatr Cogn Disord. 2009;27(1):76-81.

23 Lee DR, McKeith I, Mosimann U, Ghosh-Nodyal A, Thomas AJ. Examining carer stress in dementia: the role of subtype diagnosis and neuropsychiatric symptoms. Int J Geriatr Psychiatry. 2013 Feb;28(2):135-41.

24 de Vugt ME, Riedijk SR, Aalten P, Tibben A, van Swieten JC, Verhey FR. Impact of behavioural problems on spousal caregivers: a comparison between Alzheimer's disease and frontotemporal dementia. Dement Geriatr Cogn Disord. 2006;22(1):35-41.

25 Cho S, Zarit SH, Chiriboga DA. Wives and daughters: the differential role of day care use in the nursing home placement of cognitively impaired family members. Gerontologist. 2009 Feb;49(1):57-67.

26 de Medeiros K, Robert P, Gauthier S, Stella F, Politis A, Leoutsakos J, et al. The Neuropsychiatric Inventory-Clinician rating scale (NPI-C): reliability and validity of a revised assessment of neuropsychiatric symptoms in dementia. Int Psychogeriatr. 2010 Sep;22(6): 984-94.

27 Cummings JL. The Neuropsychiatric Inventory: assessing psychopathology in dementia patients. Neurology. 1997 May;48(5 Suppl 6):S10-6. 